\title{
Key lessons from a mixed-method evaluation of a postnatal home visit programme in the humanitarian setting of Gaza
}

Irene de Vries, ${ }^{1}$ Bassam Abu Hamad, ${ }^{2,3}$ Margo van Gurp, ${ }^{1}$ Sandra Alba, ${ }^{1}$ Umaiyeh Khammash ${ }^{2}$ and Pam Baatsen ${ }^{1}$

${ }^{1}$ KIT Health, KIT Royal Tropical Institute, Amsterdam, the Netherlands (Correspondence to: I. de Vries: i.d.vries@kit.nl). ${ }^{2}$ Juzoor for Health and Social Development, Ramallah, Palestine ${ }^{3}$ Gaza School of Public Health, Al Quds University, Gaza, Palestine.

\begin{abstract}
Background: The World Health Organization recommends postnatal home visits to improve maternal and newborn health. Evidence of postnatal home visit effectiveness in humanitarian settings is limited.

Aims: To evaluate postnatal home visits implemented in the constrained humanitarian context of Gaza.

Methods: Qualitative data were obtained through key informant interviews, in-depth interviews and/or focus group discussions with women targeted by the programme, nontargeted women, husbands, and home visitors. These data were complemented by a secondary analysis of quantitative data from existing household surveys and project monitoring data. Qualitative data were analysed using thematic analysis, and quantitative data were analysed to describe trends over time.

Results: Women in the programme demonstrated improved breastfeeding practices and increased uptake of breastfeeding, and behavioural changes reduced harmful traditional norms and practices. The programme increased mutual understanding and respect between health providers and women, allowed for a more personalized approach and increased self-esteem among the women. To improve postnatal care throughout the population, interventions should focus not only on home visits but also address immediate postnatal care in maternity, postnatal follow-up in clinics, and improvements in the coordination and communication between the different levels of care.
\end{abstract}

Conclusion: Implementation of postnatal home visits in a constrained humanitarian context such as Gaza is feasible and positively contributes to breastfeeding and newborn care practices, as well as to improved interactions between health providers and their clients. Positive effects could be leveraged if postnatal care were strengthened throughout the continuum of care.

Keywords: postnatal care, home visit, humanitarian setting, breastfeeding, newborn care practices

Citation: de Vries I; Abu Hamad B; van Gurp M; Alba S; Khammash U; Baatsen P. Key lessons from a mixed-method evaluation of a postnatal home visit programme in the humanitarian setting of Gaza. East Mediterr Health J. 2021;27(6):546-552. https://doi.org/10.26719/emhj.21.005

Received: 20/04/20; accepted: 25/10/20

Copyright (C) World Health Organization (WHO) 2021. Open Access. Some rights reserved. This work is available under the CC BY-NC-SA 3.o IGO license (https://creativecommons.org/licenses/by-nc-sa/3.o/igo)

\section{Introduction}

Home visits in the first week after birth are recommended to improve maternal and newborn care (1). The World Health Organization (WHO) recommendation is based on evidence from a systematic review in which home visits were associated with a significant reduction in neonatal mortality and improved neonatal care practices, including clean cord care, delayed bathing and early initiation of breastfeeding $(2,3)$. The impact of postnatal home visits on maternal health is less evident. A Cochrane review did not show improvements in maternal mortality or morbidity, but home visits were positively associated with motivation for exclusive breastfeeding and satisfaction with postnatal care (4). There is limited evidence about the role of these home visits in humanitarian settings.

In 2018 an independent formative evaluation was conducted of the United Nations Children's Fund (UNICEF)'s Postnatal Home Visit (PNHV) programme in Gaza, Palestine. The programme started in 2011 and is implemented by the Ministry of Health and two civil society organizations, together covering all 5 governorates of Gaza. The main objective is to reduce maternal and neonatal mortality and morbidity by ensuring the continuation of care after discharge from the maternity ward, which happens within $<6$ hours after delivery for most women in Gaza (5). These goals are met through: (1) training of 36 midwives and nurses on the national postnatal care protocol including home-based postnatal care, neonatal care, postpartum complications, behavioural change communication, and early childhood development; (2) providing them with postnatal home visit kits; and (3) conducting home visits within 48-72 hours postnatally. The home visits complement clinical visits that are still the main point of contact for most postnatal women, especially for their second and third visits. If needed, the second visit after 1 week and a third visit after 6 weeks can also be conducted at home. Through counselling and physical check-up of both the mother and the newborn infant, these visits aim to contribute to the early detection of physical and mental health problems, timely referral, preventive care, physical exercise, hygiene, responsive parenting, family planning, nutrition and breastfeeding, and promote follow-up visits at the health centre for postnatal check-ups and immunization (6). There is insufficient funding to cover 
all mothers and newborn infants in Gaza; therefore, the programme focuses on high-risk cases and primiparous women. The criteria for a high-risk pregnancy are guided by the maternal and child health book that is distributed to all pregnant women in Gaza (Table 1).

The objective of this paper is to contribute to filling the knowledge gap on PNHVs in humanitarian settings by describing key lessons of the evaluated effectiveness of the intervention and provide insights on equity and perceptions of care.

\section{Methods}

This mixed-methods study included primary qualitative data and reanalysis of existing quantitative data. Ethical approval was obtained from the UNICEF Institutional Review Board. Qualitative data collection took place between 8 February and 10 March 2018 by 6 trained Palestinian female researchers. In total, 51 individuals were interviewed and 10 focus group discussions (FGDs) took place involving 79 individuals. Participants, purposefully selected through medical records, included women served by the programme, husbands of women in the programme, midwives/nurses that conducted home visits, and women who were not visited despite being at high risk. Interviews were performed in Arabic, lasted approximately 1 hour and were conducted at the homes or offices of interviewees. FGDs, conducted at safe community-based organizations, had an average of 8 participants and duration of 2 hours. Interviews and FGDs were digitally audio-recorded. Written consent was obtained from all participants. The recordings were transcribed and directly translated into English. A coding framework was applied for thematic analysis (7).

A quantitative baseline was not available and a control site was not feasible in the context of Gaza.
Quantitative data for secondary analysis were obtained from the Ministry of Health Annual Reports 2010-2016 (8), Multiple Indicator Cluster Survey (MICS) datasets from 2010 and 2014 (9), publications from the Palestinian Central Bureau of Statistics (10) and descriptive statistics that were extracted from the programme annual reports from 2011 to 2015. Population data on periodically collected indicators such as exclusive breastfeeding and yearly registered births were compiled from the different datasets and analysed in RStudio. The indicators were displayed graphically to describe changes over time. MICS data from 2010 and 2014 were used to estimate the proportion and characteristics of women with a live birth who were eligible for the programme.

\section{Results}

The number of household visits increased on a yearly basis from $5.4 \%$ of all registered births in 2011 to $12.9 \%$ in 2016. Reanalysis of MICS data showed that an estimated $45.3 \%$ (2010) to $55.3 \%$ (2014) of all women with a live birth in the past 2 years in Gaza had any of the risk factors for inclusion (Table 1) or were primigravida during their last pregnancy. Therefore, the number of women that were eligible for the programme was higher than the current coverage.

Women and healthcare providers both reported newborn and maternal morbidity that they believed would have been detected too late without the PNHV programme. Many believed that early detection of these cases saved lives. However, Palestinian statistics were not able to reinforce these beliefs on mortality impact. The neonatal mortality rate stagnated between 2005-2009 (11.4 per 1000 live births) and 2010-2014 (11.5 per 1000 live births).

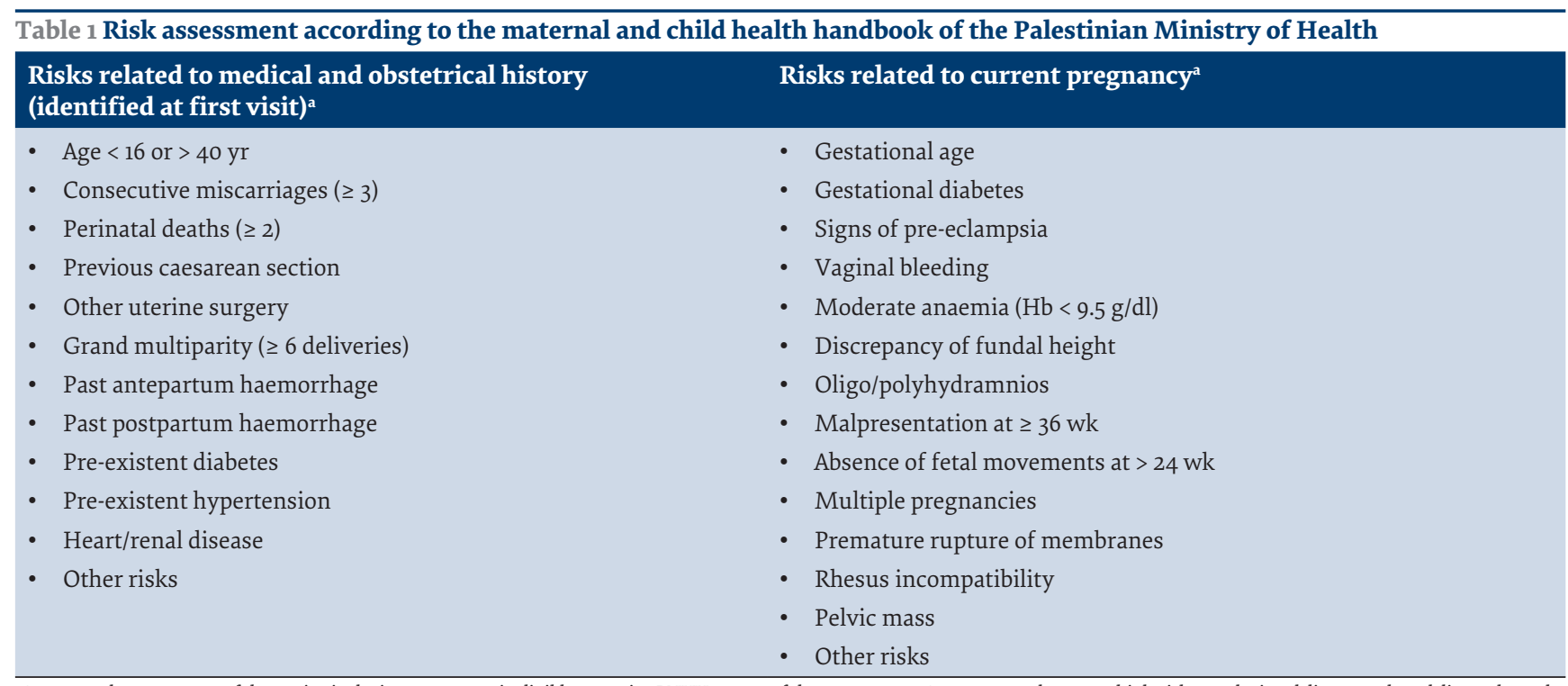

${ }^{a}$ A woman that meets one of these criteria during pregnancy is eligible to receive PNHV as part of the programme. A woman can become a high-risk case during delivery, such as delivery through caesarean section or postpartum haemorrhage. Monitoring data did not provide data on the numbers of women included for each criterion. Hb $=$ haemoglobin. 


\section{Breastfeeding}

Qualitative data revealed that women felt encouraged to breastfeed and increasingly recognized the benefits of breastfeeding. First-time mothers especially benefited, but multiparous women also mentioned that they learned new facts about breastfeeding and about storing expressed milk in the refrigerator, allowing exclusive breastfeeding for a longer period compared to previous pregnancies: "Without the midwife, I wouldn't have known how to hold and breastfeed the baby. My family felt happy. I didn't breastfeed my previous children. They drank artificial milk." (FGD visited women, Rafah)

Through the training, home visitors felt better equipped with the knowledge and skills to make breastfeeding successful. The home visitors were identified as strong agents for change who often had to fight against wrong beliefs about the benefits of artificial milk, not only by the community but also from doctors who prescribed artificial milk for the treatment of (physiological) jaundice.

Within all stakeholder groups it was mentioned that the impact on breastfeeding was the main success of the programme. Secondary analysis of MICS data showed an increase in exclusive breastfeeding in Gaza children aged $<6$ months from $14.5 \%$ in 2000 to $36.4 \%$ in 2014 . This increasing trend began before the start of the programme, followed by a steeper increase between 2010 and 2014, simultaneously with the introduction of the programme. The absolute difference of this steep increase was 8.6 percentage points and it was significant (95\% confidence interval: $1.7-15.6 \%$ ). However, due to the absence of a control site it was not possible to prove attribution to the programme.

\section{Family planning}

Through qualitative data it appeared that cultural norms had a stronger influence on family planning than the programme had. Often the husband or mother-in-law decided whether a woman would use family planning.

"I tried my best with her. I said the lady is studying at university and she needs a break between pregnancies. There are a lot of women who get pregnant directly after the 40th day postnatal. But she (the mother-in-law) refused and said "No, we are helping in raising them up". On the second visit, I found that her door was locked by her mother-in-law. I had to receive permission from the mother-in-law in order to do the visit, and the mother-inlaw had to be present." (FGD health providers for south and midzone)

Women will often not use family planning until they have reached the desired number of children, including at least 1 boy. There is a worry that contraceptives affect fertility. Analysis of trends over time with secondary data showed that Gaza's contraceptive prevalence rate increased between 2000 and 2014, with currently little over $40 \%$ of married women (aged 15-49 years) using any modern form of contraceptives. There was no noticeable change since the introduction of the programme.

\section{Traditional norms and practices}

Through home visits, nurses and midwives became more aware of the many traditional practices present within families. It gave them the opportunity to counsel and change habits.

"Through this project I got to know a lot of different cultures. During our visits, I saw many false traditions, like using oil and salt for the umbilicus. Some people use ink for it. We tried to change these bad habits for people, and we noticed the disappearance of this through the last year, as a result of this project; we increased people's awareness." (FGD health providers for south and midzone)

In addition to oil and salt application, home visitors found practices for the baby such as starch on the navel or twisting the navel with a horsetail hair, immediate bathing after delivery, herbal teas to prevent flatulence, crystalized sugar for the treatment of jaundice, tight wrapping of the baby, eye liner obstructing the lacrimal ducts, and the use of bitter substances for weaning off breastmilk. Many women said the counselling regarding traditional practices was new but informative and changed their habits.

\section{Fathers}

There seemed to be a general belief that men do not have a role in women's affairs. "It is not part of our culture" was often heard, and in some maternal and child health clinics, the presence of men was even forbidden. Qualitative data showed that level of participation and to what extent this was desired varied among women, husbands and healthcare providers. Fathers were often not encouraged to be present and some home visitors asked men not to participate because they felt embarrassed to ask certain questions. Other home visitors told about husbands that encouraged the programme and enjoyed participation, shared responsibilities of care, helped the nurse in her work and encouraged their wives to follow the nurse's advice. Some husbands that were interviewed were not interested in being present or informed, whereas others thought they were benefiting from the home visit, which increased their motivation to support their wives and children: "That encouraged me to take care of my kids more and more, and these things calm my wife down, and the kids love me more and more. My daughter related to me so much." (husband from midzone)

The same variation was found among women. Some women said they would not encourage the presence of their husband, but many also mentioned feeling emotionally supported when their husband was involved in care.

\section{Equity}

Although congenital anomalies were one of the leading causes of neonatal mortality in Gaza, no special attention was given to women with disabilities or children with congenital disabilities. Additionally, there were no criteria for inclusion based on social risks, such as economic 
status, distance to a facility, literacy rate or (social) problems at home. Women with the lowest education profiles were less likely to be included in the programme: women with primary or elementary education accounted for $0.6 \%$ of the women who attended, compared to an estimated $3.6 \%$ in the overall high-risk population (4).

Qualitative data showed that women in rural areas risked being left behind. Some midwives and nurses avoided visiting border or rural areas because they feared sexual harassment, or attacks by dogs. Ambulances could not easily reach houses in rural areas due to road conditions.

\section{Perceptions of care}

The programme in many cases increased mutual understanding and respect between healthcare providers and women. Healthcare providers mentioned that home visits made them kinder, more sensitive and improved their relationship with mothers and their families: "We learned to become humble and more human with people from the home visit; we have a kind relationship with them as a result of that." (FGD health providers from south)

Women mentioned feeling valued and cared for and that the home visit raised their self-esteem. In general, women were highly satisfied with the programme and appreciated the attitude of providers. These feelings increased trust in the healthcare system and motivated patients to make better use of care. Due to the PNHVs, women and their families were more aware of the importance of postnatal care. However, while many women went or wanted to go for clinical follow-up, barriers persisted relating to transport, care for other children, crowds at facilities, bad attitudes of staff in facilities, lack of privacy and lack of drugs. Although women were generally positive about the programme, they were also frustrated about the lack of continuity of care after the home visits ceased. Some of the nurses complained that women would continue calling them with questions.

\section{Discussion}

This mixed-method study provides valuable insights into Gaza's PNHV programme, triangulating data from multiple sources. However, the strengths of quantitative approaches could not be fully leveraged. Due to the observational study design without a baseline or control site, a counterfactual quantitative assessment to attribute changes in health indicators was not possible. This drawback was further compounded by the lack of programme-specific monitoring data. The statistics of the programme reports were insufficient, not consistently measured throughout the years, and could not be linked to individuals.

Key findings of the programme related to qualitative aspects, such as improved breastfeeding practices and transformative behaviour towards cord care, bathing and the use of substances, such as herbal teas, crystalized sugar or eyeliner, for the newborn. Secondary quantitative data showed a significant steep increase for exclusive breastfeeding of children aged $<6$ months in Gaza after implementation of the programme. While it was not possible to prove attribution, the programme may have been a trigger for this increase because qualitative data indicated that women had a changed attitude towards and increased motivation to continue breastfeeding. The contributions of the programme to breastfeeding and newborn care practices are in line with those in the international literature $(3,4,11-14)$. The time and focused attention for custom advice was highly valued by the mothers and contributed to this success. In many instances, the programme increased mutual understanding and respect between healthcare providers and women. This shows how a personalized approach can help motivate women and those around them to exclusively breastfeed and apply healthy newborn care practices. It also shows how services can be enhanced through better relationship building.

The study was not able to confirm an effect on mortality, despite evidence in other settings $(2,12,14)$. Qualitative data revealed that detection and referral of complications seemed to happen, but these observations could not be underpinned with statistical evidence from the programme or national data. Given that the programme covers $<13 \%$ of total live births in Gaza, any impact of the initiative on mortality at the regional level seems rather unrealistic. The low coverage rate of PNHVs is similar to programmes in other countries. A review of PNHV programmes implemented at scale in 12 Asian and African countries showed that programme coverage is generally too low to have a meaningful impact on maternal and newborn mortality (15).

The effects of the programme on family planning will remain limited without active involvement of husbands or mothers (in law). International literature is scarce on the role of fathers in postnatal care and often limited to the effects on breastfeeding $(16,17)$. Qualitative data from this evaluation show that, even while people tend to think that men should not or do not want to be involved, the reality is often different and there should be room to customize to the family's situation. Out of respect for both women and their husbands, the presence of the latter should at least be allowed and proposed as an option during care in the clinic and at home. Healthcare providers should be encouraged and empowered to promote involvement of fathers and enhance their competency for including fathers.

Scarce resources seem to justify the focus on highrisk cases, but even these are only partially served. Risk stratification of the programme was based on medical characteristics only and no criteria were developed for inclusion based on social risks. Nevertheless, populations who are socially at risk, might benefit more from postpartum support to improve parenting skills and enhance maternal mental and physical health and quality of life (18).

The findings of this evaluation confirm that the implementation of PNHVs cannot be a stand-alone 
intervention but requires a broader health system approach. The remaining barriers to visit a clinic show that an effect on postnatal follow-up visits cannot be expected unless facility care is enhanced as well. The tenacious calls of women to home visitors after ending a providerclient relationship show that women need a trustworthy accessible source for information. Additionally, the programme does not address the problem of early discharges from maternity wards (5), while the immediate postnatal period provides many opportunities for care and counselling, including instruction on the early initiation of breastfeeding. When determining whether and how to use PNHVs, context and local feasibility need to be considered, rather than looking at the absolute effectiveness of the intervention (15). To improve access to quality postnatal care throughout Gaza, a more holistic approach is needed to strengthen and connect postnatal care at different levels, including at the hospital, clinic and at home. Factors contributing to success, such as personalized care with appropriate time investment and focused attention, can be provided anywhere and should be enhanced throughout all levels of care. Facility care can be complemented with home-based care for individuals who are at high risk or not able to come to the clinic and, in line with WHO recommendations (1), supplemented with additional telephone- or web-based contacts.

\section{Conclusion}

This study shows that the implementation of postnatal home visits in a constrained humanitarian setting is feasible and can enhance breastfeeding practices, identify (life-threatening) maternal and neonatal complications and promote newborn care practices, as well as improving client-provider interactions. However, there are challenges in achieving appropriate and equal postnatal care coverage. Positive effects of the programme could be leveraged if postnatal care is strengthened throughout the continuum of care with an added focus on immediate postnatal care in the maternity wards, in addition to customized and personalized postnatal care in primary care facilities.

\section{Acknowledgement}

The authors would like to thank all those who contributed to the evaluation, especially the women, fathers, home visitors and key stakeholders who were interviewed or participated in FGDs. In addition, we would like to thank the experienced qualitative data collectors for their work: Shrooq Abu Hamad, Mayson Turban, Amal Sarsour, Nadeen Al Radassi, Kholoud Al Sedawi, and Eman Abu Hamra. They provided us with rich, elaborate data. Special appreciation goes to UNICEF and the programme implementing partners, $\mathrm{MoH}$ and the two involved CSOs, for making this study possible.

Funding: Conducting the evaluation and writing of this manuscript were financially supported by UNICEF. UNICEF and partners were involved in the evaluation and participatory development of recommendations through an Evaluation Steering Committee. The researchers and authors of this article are independent and remained objective. UNICEF was not able to influence the findings of the study. UNICEF approved publication of this manuscript and did not make changes that would influence the results.

Competing interests: None declared.

\section{Enseignements clés d'une évaluation à méthode mixte d'un programme de visites postnatales à domicile dans le contexte humanitaire de Gaza}

\section{Résumé}

Contexte: L'Organisation mondiale de la Santé recommande des visites postnatales à domicile pour améliorer la santé maternelle et néonatale. Les preuves de l'efficacité de ces visites dans les situations humanitaires sont limitées.

Objectifs : Évaluer les visites postnatales à domicile mises en place dans le contexte humanitaire caractérisé par des restrictions de Gaza.

Méthodes: Des données qualitatives ont été obtenues par le biais d'entretiens avec des informateurs clés, d'entretiens approfondis et/ou des groupes de discussion thématique avec des femmes ciblées par le programme, ainsi qu'avec des femmes, des maris et des visiteurs à domicile non ciblés. Ces données ont été complétées par une analyse secondaire des données quantitatives des provenant enquêtes auprès des ménages existantes et des données de suivi des projets. Les données qualitatives ont été analysées à l'aide d'une analyse thématique, et les données quantitatives ont été examinées pour décrire les tendances dans le temps.

Résultats: Les femmes participant au programme ont montré une amélioration des pratiques d'allaitement au sein et une adoption accrue de ce mode d'allaitement et les changements de comportement ont permis de réduire les normes et pratiques traditionnelles néfastes. Le programme a amélioré la compréhension et le respect mutuels entre les prestataires de soins et les femmes, a permis une approche plus personnalisée et a renforcé l'estime de 
soi des femmes. Pour améliorer les soins postnatals dans l'ensemble de la population, les interventions devraient se concentrer non seulement sur les visites à domicile, mais aussi porter sur les soins postnatals immédiats à la maternité, le suivi postnatal dans les dispensaires et les améliorations de la coordination et de la communication entre les différents niveaux de soins.

Conclusion : La mise en œuvre des visites postnatales à domicile dans un contexte humanitaire caractérisé par des restrictions comme celui de Gaza est réalisable et contribue positivement aux pratiques d'allaitement au sein et de soins aux nouveau-nés, ainsi qu'à l'amélioration des interactions entre les prestataires de santé et leurs clients. Les effets positifs pourraient être mis à profit si les soins postnatals étaient renforcés tout au long du continuum des soins.

$$
\begin{aligned}
& \text { الدروس المستفادة من التقييم القائم على مزيج من الأساليب لبرنامج الزيارات المنزلية بعد الولادة، في ظل الأوضاع }
\end{aligned}
$$

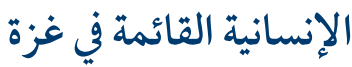

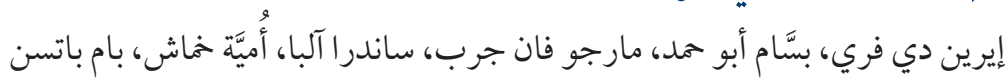

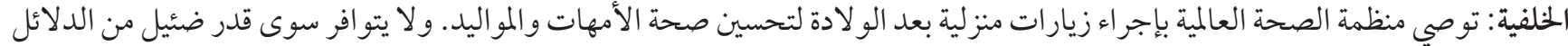

$$
\begin{aligned}
& \text { على فعالية الزيارات المنزلية بعد الو لادة في الأوضاع الإنسانية المانية. }
\end{aligned}
$$

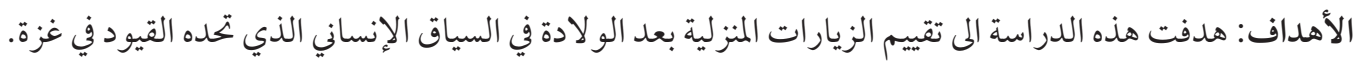

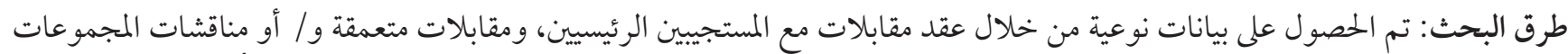

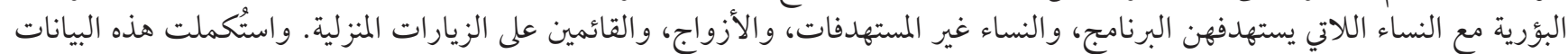

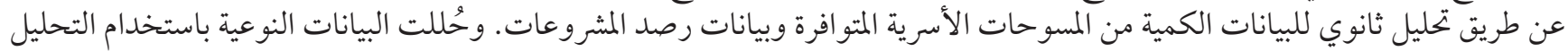

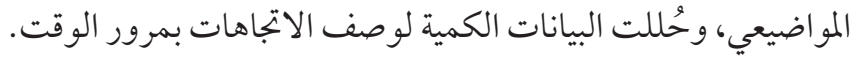

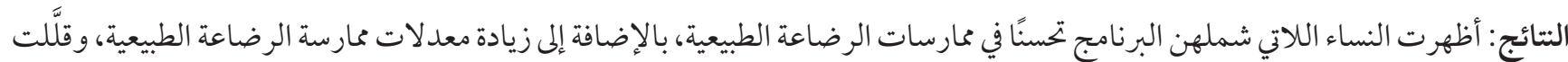

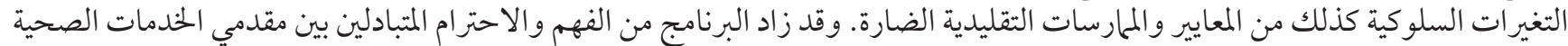

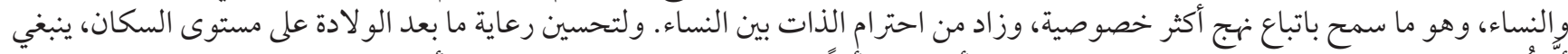

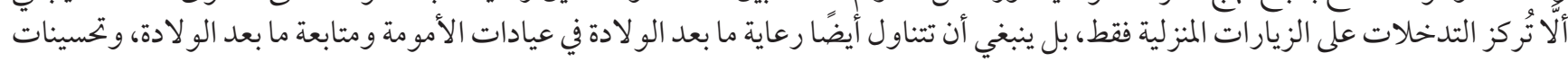
التنسيق و التو اصل بين نختلف مستويات الزيار الرعاية.

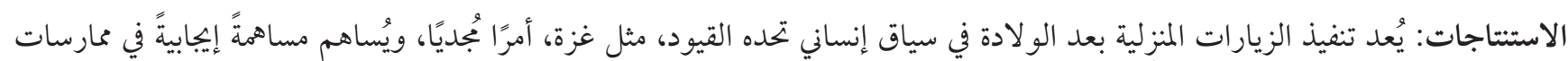

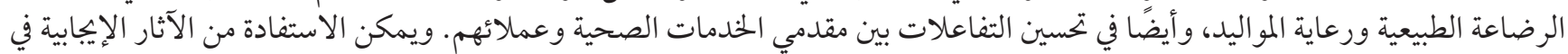
حالة تعزيز رعاية ما بعد الو لادة على امتداد سلسلة الرئل الرعاية.

\section{References}

1. WHO recommendations on postnatal care of the mother and newborn. Geneva: World Health Organization; 2013 (https://www. who.int/maternal_child_adolescent/documents/postnatal-care-recommendations/en/, accessed 23 January 2021).

2. Gogia S, Sachdev HS. Home visits by community health workers to prevent neonatal deaths in developing countries: a systematic review. Bull World Health Organ. 2010 Sep 1;88(9):658-66b. https://doi.org/10.2471/BLT.09.069369. PMID:20865070

3. Gogia S, Sachdev HP. Home-based neonatal care by community health workers for preventing mortality in neonates in lowand middle-income countries: a systematic review. J Perinatol. 2016 May;36 Suppl 1:S55-73. https://doi.org/10.1038/jp.2016.33. PMID:27109093

4. Yonemoto N, Dowswell T, Nagai S, Mori R. Schedules for home visits in the early postpartum period. Evid Based Child Health. 2014 Mar;9(1):5-99. https://doi.org/10.1002/ebch.1960 PMID:25404577

5. Palestinian Central Bureau of Statistics. Palestinian multiple indicator cluster survey 2014. Ramallah: Palestinian Central Bureau of Statistics; 2015 (http://www.pcbs.gov.ps/Downloads/book2099.pdf, accessed 23 January 2021).

6. Baatsen P, Vries ID, Hamad BA, Khammash U, Alba S, Gurp MV. Evaluation of a postnatal home visiting programme for mothers, neonates and their families in Gaza, state of Palestine, over the period 2011-2016. Amsterdam: KIT Royal Tropical Institute; 2018 (https://www.kit.nl/publication/evaluation-of-a-postnatal-home-visiting-program-for-mothers-neonates-and-their-families-in-gaza-state-of-palestine-over-the-period-2011-2016/, accessed 23 January 2021). 
7. Gale NK, Heath G, Cameron E, Rashid S, Redwood S. Using the framework method for the analysis of qualitative data in multi-disciplinary health research. BMC Med Res Methodol. 2013 Sep 18;13:117. https://doi.org/10.1186/1471-2288-13-117 PMID:24047204

8. Palestine National Authority Ministry Of Health. Statistical reports (https://www.site.moh.ps/index/Books/BookType/2/Language/ar, accessed 11 September 2018).

9. UNICEF. MICS datasets [website] http://mics.unicef.org/surveys (accessed 23 January 2021).

10. Palestinian Central Bureau Of Statistics Publications [website] http://www.pcbs.gov.ps/pcbs_2012/Publications.aspx (accessed 23 January 2021).

11. Kirkwood BR, Manu A, Asbroek AHt, Soremekun S, Weobong B, Gyan T, et al. Effect of the newhints home-visits intervention on neonatal mortality rate and care practices in Ghana: a cluster randomised controlled trial. Lancet. 2013 Jun 22;381(9884):2184-92. https://doi.org/10.1016/So140-6736(13)60095-1 PMID:23578528

12. Hanson C, Manzi F, Mkumbo E, Shirima K, Penfold S, Hill Z, et al. Effectiveness of a home-based counselling strategy on neonatal care and survival: a cluster-randomised trial in six districts of rural southern Tanzania. PLoS Med. 2015;12:e1001881. https:// doi.org/10.1371/journal.pmed.1001881 PMID:26418813

13. Waiswa P, Pariyo G, Kallander K, Akuze J, Namazzi G, Ekirapa-Kiracho E, et al. Effect of the Uganda newborn study on care-seeking and care practices: a cluster-randomised controlled trial. Glob Health Action. 2015;8:24584. https://doi.org/10.3402/gha. v8.24584 PMID:25843498

14. Lassi ZS, Bhutta ZA. Community-based intervention packages for reducing maternal and neonatal morbidity and mortality and improving neonatal outcomes. Cochrane Database of Systematic Reviews 2015;3:CDoo7754. https://doi.org/10.1002/14651858. CDoo7754.pub3.

15. McPherson R, Hodgins S. Postnatal home visitation: lessons from country programs operating at scale. J Glob Health. 2018 Jun;8(1):010422. https://doi.org/10.7189/jogh.08.010422 PMID:29977530

16. Hunter T, Cattelona G. Breastfeeding initiation and duration in first-time mothers: exploring the impact of father involvement in the early post-partum period. Health Promot Perspect. 2014 Dec 30;4:132-6. https://doi.org/10.5681/hpp.2014.017 PMID:25649998

17. Rempel LA, Rempel JK, Moore KCJ. Relationships between types of father breastfeeding support and breastfeeding outcomes. Matern Child Nutr. 2017 Jul;13(3):e12337. https://doi.org/10.1111/mcn.12337 PMID:27460557

18. Shaw E, Levitt C, Wong S, Kaczorowski J. Systematic review of the literature on postpartum care: effectiveness of postpartum support to improve maternal parenting, mental health, quality of life, and physical health. Birth. 2006 Sep;33(3):210-20. https:// doi.org/10.1111/j.1523-536X.2006.00106.x PMID:16948721 